Chuva é cantoria na aldeia dos mortos. Diretores: Reneé Nader Messora e João Salaviza. Produção: Brasil, Portugal. 2018. 113 min. cor.

\title{
Amanda Horta
}

\section{(2) OpenEdition Journals}

Edição electrónica

URL: http://journals.openedition.org/aa/7717

DOI: $10.4000 /$ aa. 7717

ISSN: 2357-738X

Editora

Programa de Pós-Graduação em Antropologia Social (UnB)

Edição impressa

Paginação: 322-326

ISSN: 0102-4302

Refêrencia eletrónica

Amanda Horta, «Chuva é cantoria na aldeia dos mortos. Diretores: Reneé Nader Messora e João Salaviza. Produção: Brasil, Portugal. 2018. 113 min. cor.», Anuário Antropológico [Online], v.46 n.1 I 2021, posto online no dia 03 janeiro 2021, consultado o 28 abril 2021. URL: http:// journals.openedition.org/aa/7717 ; DOl: https://doi.org/10.4000/aa.7717

\section{@(@) $\Theta \Theta$}

Anuário Antropológico is licensed under a Creative Commons Atribuição-Uso Não-Comercial-Proibição de realização de Obras Derivadas 4.0 International. 


\title{
anuário antropológico
}

v. $46 \cdot n .1 \cdot j a n e i r o-a b r i l \cdot 2021.1$

\section{Chuva é cantoria na aldeia dos mortos. Diretores: Reneé Nader Messora e João Salaviza. Produção: Brasil, Portugal. 2018. 113 min. cor.}

DOI: https://doi.org/10.4000/aa.7717

\begin{abstract}
Amanda Horta • Universidade Federal de Ciências da Saúde de Porto Alegre - Brasil
Graduada em Ciências Sociais pela UFMG (2010), mestre e doutora em Antropologia Social pelo Museu Nacional da UFRJ (2013 e 2018). Desenvolve pesquisa junto às populações do Território Indígena do Xingu, com ênfase nas experiências indígenas no espaço urbano de Canarana (MT). Filiada ao Grupo de Pesquisa Saúde Coletiva, Epistemologias do Sul e Interculturalidades da Universidade Federal do Sul da Bahia (UFSB) e ao Laboratório de Alteridades do Departamento de Educação e Humanidades (DEH) da Universidade Federal de Ciências da Saúde de Porto Alegre (UFCSPA).
\end{abstract}


Lançado em 2018, o filme de Reneé Nader Messora e João Salaviza, produzido na aldeia Pedra Branca, traz um retrato sensível da vida na Terra Indígena Krahô, neste início de século. Por um lado, o filme preza por sua precisão, evidenciando a particularidade da situação que apresenta e recusando endereçar-se, de maneira genérica, à questão indígena brasileira. Para um espectador alheio às nuances da questão indígena no Brasil - que é, certamente, o caso da maior parte da população do país -, o filme narra, de forma cuidadosa, as sutilezas das experiências pessoais das personagens, tensionando os limites entre ficção e realidade. Por outro lado, para aqueles que conhecem a vida no interior do Brasil, nas terras indígenas e fora delas, "Chuva..." conta uma história que remete a tantas outras histórias indígenas, de suas relações na aldeia e nas cidades do entorno. De fato, narrativas sobre a mobilidade e as experiências indígenas nas cidades vêm ganhando destaque nos trabalhos acadêmicos. Entretanto, tal realidade segue invisibilizada no cenário nacional mais amplo, com efeitos perversos para a defesa dos direitos originários destas populações. Para romper as cortinas pesadas que ocultam as vidas indígenas no Brasil, o filme aposta numa narrativa contada desde o ponto de vista de um jovem krahô, em um filme que mobiliza afetos de leigos e especialistas em assuntos indígenas.

"Chuva...” conta a história de Ihjãc, um jovem homem krahô casado com Kôtô, pai de um bebê que ainda não aprendeu a andar. Muitas vezes, é difícil manter em mente o fato incontornável de que a cena a que assistimos depende da imposição de uma câmera, tamanha a sensação de intimidade expressa nas imagens. A trama se desenrola nas interseções entre os três mundos que a vida do rapaz requer articular: a aldeia dos parentes, a aldeia dos mortos e a cidade dos brancos. Nenhum destes mundos é ficcional. A aldeia dos parentes chama-se Pedra Branca e fica no limite da Terra Indígena Krahô, região nordeste do Tocantins. Ali os Krahô vivem entre parentes, falam sua língua materna, produzem seus alimentos. A aldeia dos mortos é aludida no início do filme, quando ouvimos o falecido pai de Ihjãc chamando-o em sonho, incitando-o a entrar nas águas de uma cachoeira e a acompanhá-lo até sua morada de morto. Ihjãc recusa. $\mathrm{O}$ tema da saudade tem destaque na importante monografia de Manuela Carneiro da Cunha sobre os Krahô, intitulada Os mortos e os outros (1978) - expressão utilizada como título da tradução inglesa do filme, The dead and the others. Os mortos sentem saudades dos vivos e, se os vivos também os desejam por tempo demais, tendem a juntar-se a eles, algo que só é possível se os que ficaram morrerem também. A saudade, então, deixa o corpo doente, vulnerável. Por isso, o luto pelos mortos - o choro, a saudade - precisa acabar, através da realização do rito fúnebre. Depois do sonho, Ihjãc convoca os parentes para abrir a roça para o ritual: é hora de terminar o luto pela morte do pai.

As três dimensões espaciais apresentadas no filme - a aldeia dos vivos, dos mortos e a cidade dos brancos - se enlaçam umas nas outras. O filme não apresenta a aldeia krahô isolada da influência dos brancos, nem, tampouco, da influência dos mortos. O paralelo entre tais influências não é vão: as sociedades ameríndias conceituam os brancos como outros "mal acomodados entre fantasmas e enti- 
dades maléficas, inimigos e afins" (ALBERT; RAMOS, 2002). De maneira similar, Carneiro da Cunha descreve a proximidade das noções krahô de morto, inimigo e afim (1978, p. 142-146). Para os ameríndios, brancos e mortos são figuras da alteridade. No filme, a influência dos brancos chega através de coisas, pessoas e ideias - o facão para abrir a roça, o candidato que visita a aldeia, a última moda dos esmaltes coloridos. A influência dos mortos chega através de sonhos, de doenças e de pajelanças. Depois de sonhar com seu pai, Ihjãc sente seu corpo cada vez mais fraco, ardendo por dentro. Mais uma vez a monografia de Carneiro da Cunha ajuda na compreensão: "a comunicação excessiva com os mortos é a principal causa de adoecimento" nas comunidades krahô (Ibid., p. 12-13).

O pajé fuma e dá o diagnóstico: o espírito da arara deseja Ihjãc, quer torná-lo pajé, tornar seus olhos capazes de ver outros espíritos (mecarõ). Mas Ihjãc não deseja se tornar pajé. O filme não explica o porquê. Parece-me, inclusive, que ao se esquivar dessa questão, "Chuva..." evidencia o fato de que filme algum - eu acrescentaria pesquisa alguma - é capaz esgotar as questões que a existência de um povo coloca. Se a razão não é explicada, o medo de Ihjãc é pungente. Buscando fugir do assédio da arara, Ihjãc ruma para a cidade.

A cidade é a terra dos brancos, um lugar marcado pelo excesso. Há sempre um rádio ligado, anúncios do comércio, forró ou música sertaneja. O barulho abafa os ouvidos - é difícil escutar as palavras faladas. As cenas em Itacajá (TO), centro urbano próximo à aldeia Pedra Branca, produzem impressões similares àquelas trazidas pelas etnografias sobre as experiências indígenas nas cidades do interior do Brasil, como é o caso da minha tese realizada na cidade de Canarana (MT), junto aos indígenas do Território Indígena do Xingu (TIX) (HORTA, 2018). Assim como os indígenas do TIX, Ihjãc parece experimentar, de maneira criativa, a vida na cidade. Ele supõe que a arara não é capaz de lhe encontrar em Itacajá, mas esta suposição, o filme deixa claro, é apenas uma hipótese que Ihjãc se dispõe a experimentar.

O primeiro destino de Ihjãc é o hospital público: ele se sente doente devido ao assédio da arara e busca a medicina dos brancos. O despreparo institucional para lidar com a questão indígena, mesmo nos hospitais onde sua presença é frequente, é mais uma realidade contumaz. Descobrimos ali que Ihjãc tem também um nome de branco: para "facilitar", os brancos o chamam de Henrique. Pouco depois, o jovem é levado para a Casa de Apoio, que abriga indígenas em tratamento ou em observação.

Na cidade, Ihjãc telefona para a aldeia perguntando ao pajé se a arara já se esqueceu dele, se ele pode voltar. Mas o rapaz não parece receber resposta. $O$ tempo passa e os brancos lhe dizem que ele "já está bom”, que não pode mais ficar na Casa de Apoio. Mas Ihjãc não quer voltar, sente medo de virar pajé. Sem abrigo, sem dinheiro, o jovem dorme na rua e parece sonhar. Um homem caminha pela cidade em trajes rituais - cocar na cabeça e guizos no pé -, com uma tocha na mão. Seria este o falecido pai de Ihjãc? Não podemos dizê-lo com certeza. Ainda assim, ao despertar, Ihjãc se põe imediatamente a caminhar de volta para a aldeia.

$\mathrm{Na}$ aldeia Pedra Branca, os parentes se preparam para a festa de fim do luto 
de seu pai. Os corpos indígenas que vemos agora são outros. Muitos têm o torso pintado, os cabelos cortados à moda krahô, "a risca característica que corre de têmpora a têmpora cuidadosamente desbastada" (CARNEIRO DA CUNHA, 1978, p. 29). A cantoria dos velhos contrasta com o silêncio que reina no princípio do filme. Depois de alegrarem o morto com a corrida de toras e de chorarem sua morte pela última vez, a comunidade se reúne. Um homem discursa sobre a importância de esquecer o morto, de deixar para trás a saudade, de reafirmar as relações com os vivos. Chove lá fora e, ainda que o filme não o diga, é difícil deixar de pensar que, como sugere o título, a aldeia dos mortos deve estar em festa. Falando baixinho ao marido, Kotô pede que ele deixe a saudade ir embora. Mas Ihjãc diz que não pode mais. "As coisas mudaram. Já não sou o mesmo. Os mecarõ... eu agora os vejo, conheço a alma das coisas". Ihjãc virou pajé.

"Chuva..." é um filme urgente em um país que fecha os olhos para o genocídio em curso de suas populações originárias. A história de Ihjãc mostra a inadequação de fórmulas simplistas que enquadram os indígenas como tradicionais ou modernos, que negam seus modos de existência por exotização ou assimilação. Certa vez, em uma cidade, um jovem Ikpeng me disse: "Para o branco, sempre tem que facilitar". Ele estava certo, penso. Os brancos tendem, de fato, a tomar o complexo por complicado, condicionando o conhecimento à redução da realidade em unidades simples. Na contramão do que pensam os brancos, "Chuva..." apresenta uma dimensão fictícia, mas possível, da vida indígena no Brasil, e o faz sem sacrificar a complexidade, nem superinterpretar as ações, concedendo o protagonismo que lhes é de direito e contribuindo, assim, para a projeção de suas vozes. 
Amanda Horta

\section{Referências}

ALBERT, Bruce; RAMOS, Alcida Rita (Orgs.). Pacificando o branco: cosmologias do contato norte amazônico. São Paulo: Unesp, 2002.

CARNEIRO DA CUNHA, Manuela. Os mortos e os outros: uma análise do sistema funerário e da noção de pessoa entre os índios Krahó. São Paulo: Hucitec, 1978.

HORTA, Amanda. Relações indígenas em Canarana. Tese (Doutorado em Antropologia Social. Universidade Federal do Rio de Janeiro, Museu Nacional, Rio de Janeiro, 2018. AZEVEDO, Dagoberto Lima. Agenciamentos do mundo pelos Kumuã Ye'pamahsã: o conjunto dos bahsese na organização do espaço Di'ta Nuhku. Manaus: EDUA, 2018. (Coleção Reflexividades Indígenas). 